\title{
Instructional Planning in Online Universities in Korea: Considering Student Stressors and Demographic Variables
}

\author{
Sunwoo Kang ${ }^{1}$ \\ ${ }^{1}$ The Center for Teaching and Learning \\ The Catholic University of Korea, Bucheon, 110-758, Republic of Korea \\ Young Sun Chung ${ }^{2}$ \\ ${ }^{2}$ Department of Counseling Psychology \\ Korea Cyber University, Seoul, 110-340, Republic of Korea
}

\begin{abstract}
The present study explores how the stress of online learners is related to Korean cultural norms and social expectation and presents the criteria online education should aim at when designing instructional approaches. A sample of 176 students from a Korean online university participated in a study investigating the patterns in the academic and personal stressors they face. This study also examines stressor types in relation to sample characteristics, analyzed with a categorization method developed by extant researchers on the stress faced by U.S. college students. Unlike the findings of previous studies on college student stress, this study's results reveal that nontraditional Korean online students were faced with (1) taking on the multiple roles at work and home prescribed by cultural and social norms, and (2) challenges in regulating study habits and the learning environment as adult learners. The relevant implications for the design of online learning are discussed.
\end{abstract}

Keywords: adult learners, designing online learning programs, nontraditional learners, online university, stressor

\section{INTRODUCTION}

\subsection{Background of the Study}

With increasing value placed on lifelong and continuing education, many Korean higher education institutes have designed and developed online learning programs using alternative delivery modes. Numerous cyber and digital universities have established technological systems and learning centers to provide robust media servers for the streaming of prerecorded or live classes. Many of these learning programs have focused on the delivery efficiency of the learning materials, and issues concerning online learning programs have been addressed in the online learning sciences [8], [33], [34], [37], [38]. Few studies have explored the mental health and well-being of online university students, however. ${ }^{1}$ As part of enhancing institutional management and assessing accountability, higher education research practitioners and college affairs professionals need to examine the gap between the advent of technology and students' ability to meet their academic and technological demands. One of the key components of understanding students' ability to learn online effectively is to explore the stressors related to their adjustment as online learners [7].

\footnotetext{
*Corresponding author. E-mail : zdorovaya_lena@catholic.ac.kr Manuscript received Jan. 17, 2011 ; accepted May.20, 2012
}

The primary goal of this article is to introduce how and why the online university partnership among administrators, faculty, and students is important in designing and delivering courses and programs in Korea's online university environment by addressing the importance of student mental health. First, we introduce the history of Korea's Lifelong Education Act and its impact on online universities and students. Second, we review the roles of cultural and societal norms and their impact on online adult learners in Korea. Third, we present an exploratory study on online adult learners and their academic and personal stressors. Finally, we discuss the importance of considering student stressors in designing online university courses in Korea.

As the popularization of lifelong education has created a trend towards e-learning, many e-learning institutes utilize the characteristics of adult learners [27], [43]. For example, researchers have stated that adult learners might face a reduced learning speed, yet adults are capable of bringing their life experiences into their learning, monitoring what is learned until they are satisfied with the learning outcome and incorporating various learning methods to meet their interests and academic needs [3], [42].

In Korea, the Lifelong Education Act was enacted by the government as a part of an education reform framework in 1999 [22], [23]. Online universities empowered by the Lifelong Education Act provide critical functions, such as widening 
educational opportunities for individuals who have not completed their formal education and providing additional learning opportunities for students who have post-secondary education yet need additional job-related or parenting training.

Online universities in Korea are often faced with financial burdens, however, that they usually must address through privatization [17]. Unlike for traditional 4-year off-line universities, government incentive funds are rarely allocated to online universities. The Korean government recently began evaluating the effectiveness of online universities. Korean online university students are nontraditional in a number of ways. Many of those who take online classes have full-time jobs. Online university students also have unique family responsibilities since they are the money makers for either themselves or their families. These students either delayed enrollment after graduating from high school or sought additional learning opportunities as returning students after obtaining college degrees [36].

\subsection{Culture and Societal Events Shaping the Roles of Korean Online Adult Learners}

Adults pursue advanced degrees or continue their education to achieve self-fulfillment, increase their marketability, and to promote excellence in their profession or discipline [49]. In Korea, education fervor has become a major phenomenon, which most parents and students exhibit. Koreans think of learning as a tool for success and of lifelong learning as a tool for lifelong earning. Korea, a relatively small but extremely populous country with very limited natural resources, suffered a series of cataclysmic events, such as the Korean War in 1950, the Oil Crisis in the 1970s, and the financial crisis in the late 1990s. Korean college students and adults became anxious about the uncertainty of their future [23], [25]. Education became the only way to survive and succeed in the competitive country. Obtaining educational credentials and refining foreign language skills have become tools for demonstrating one's competency. Education fervor became a national trend and an obsession among Korean adolescents and adults [26]. Online universities have facilitated Koreans' zeal to pursue academic acceleration by providing numerous online classes and programs in various subjects.

Nontraditional students learning online are unique because they are facing the demands of their conflicting roles in their family relationships [8], [18], [48]. Unlike students attending 4year colleges immediately after graduating high school (i.e., traditional college students), many adult online learners are in different developmental stages. Online university students in Korea are taking leading familial roles by being financially independent or, sometimes, by financially supporting their families. Many must also meet work-related demands. Functioning as a full-time student while also engaged with families and full-time jobs is particularly challenging.

Korean culture is strongly influenced by Confucianism [23], [25]. Confucian norms dictate what individuals should do and how they should think and behave. Women are expected to be caring with their children and husbands. Men are expected to be the head of the family by providing financial resources. However, social roles in Korea have become more complex through a series of cataclysmic events, especially the financial
The roles of online universities in Korea have become critical in widening access to online learning outside of the formal school system.

crisis of the late 1990's. The traditional image of the father as the financial provider changed after the financial crisis hit Korea strongly. More Korean women than ever are choosing to have full-time jobs, burdening them with job-related responsibilities as well as family obligations [27]. The stress flowing from their multiple roles has become one of the barriers adult online learners must overcome.

\subsection{The Stress of Nontraditional Adult Learners}

Stress is known as the outcome of an imbalance between environmental demands and individual resources [16], [20], [29]- [31]. Stress weakens learners' cognition and emotions. Severe and prolonged stress can cause burnout and cognitive deficits [42], [44].

In a study examining the effect of performance on well-being, researchers demonstrated that individuals able to respond to the specific demands of a given task may also be able to control (or moderate) the impact of high demands on their well-being [44]. It has been postulated that nontraditional adult learners who have extensive work experience may be better able to process the high demands of work, which also positively affects their outcomes [29]. Several studies have also examined academic orientation and achievement among nontraditional students [4], [13], [15]. However, these studies mostly involved adult and nontraditional learner samples collected predominantly from campuses in North America. In addition, studies have been conducted on the stress and needs of traditional students attending college at a normal pace [11], [14], [23], [25], [36], [39]. Most of the findings suggest that traditional college students experience stress relating to meeting the academic demands of obtaining a college degree (e.g., grades, competition, deadlines, exams, expectations from family or partners in intimate relationships).

Although stress and coping may seem common to both traditional and nontraditional college students, the stress of nontraditional students learning online may be qualitatively different. Research addressing stress among nontraditional online learners needs to be explored.

\subsection{Purpose of the study}

The present study explores (1) the stressors of nontraditional adult students enrolled in an online Korean university by using open-ended survey items and (2) the relation between specific groups and stressor types. The needs and voices of online adult learners may go unidentified if this method is not employed. By paying attention to what students encounter, the higher education professionals of online universities can develop and provide programs that enhance students' cognitive and emotional resourcefulness. Allowing participants to describe the stressors they encounter through their own voices and opinions will allow for a better understanding of student needs. Therefore, Likert-type scales were not considered for the present study. Its purpose is not to test whether it measures what it purports to measure but to capture students' authentic responses and voices via methods used in previous studies [1], 
[6], [23], [34]. The adopted method specifically explores participants' perceptions and opinions rather than to suggest responses based on Likert-type scales. This study assumes that students were honest in their responses and that open-ended items capture as much as possible of what students were willing to express. The research questions are listed below.

Research question 1. Are there relations between academic stressors and Age Group?

Research question 2. Are there relations between personal stressors and Age Group?

Research question 3. Are there relations between academic stressors and marital status?

Research question 4. Are there relations between personal stressors and marital status?

Research question 5. Are there relations between academic stressors and change of major?

Research question 6. Are there relations between personal stressors and change of major?

\section{METHOD AND ANALYSIS}

\subsection{Survey}

The survey included two open-ended items that asked participants to describe their top two personal and academic stressors. Specifically, students were asked to describe briefly two situations that they found the most stressful in two areas of their lives, (a) academic and (b) personal.

\subsection{Participants and Procedure}

The participants comprised 176 undergraduate students (26 males, 139 females, and 11 who did not specify a gender) enrolled in a cyber university in Korea. The majority were female; thus, gender comparison is not considered. Participants' ages ranged from 24 to 52 years $(M=35.39, S D=7.61)$. Excluding those who did not specify an employment status or who specified it as "other," $70 \%$ of the participants reported having full-time jobs. The details of the sample description are presented in Table 1.

Table 1. The demographic description of the sample, with the demographic variables

\begin{tabular}{ll}
\hline $\begin{array}{c}\text { Demographic } \\
\text { Variable }\end{array}$ & \multicolumn{1}{c}{$\begin{array}{c}\text { Frequency (in percent) or } \\
\text { Mean (Standard Deviation) }\end{array}$} \\
\hline Sex & Male 26 (14.77\%) \\
& Female 139 (78.98\%) \\
& Unspecified $11(6.25 \%)$ \\
Age & $M=35.39, S D=7.61$
\end{tabular}

Job type Unemployed (22\%; homemakers $21 \%$, other $1 \%)^{*}$

Educational and research practitioners (19\%)

Office workers (18\%),

Religious practitioners (6\%)

Public service workers (5\%)

Technicians (4\%)

Accountants (3\%)

Nurses (2\%)

Full-time students (2\%)

Unspecified (19\%)

Data were collected from November to December of 2010. The survey included two open-ended items on personal and academic stressors. Participants were asked to describe the top two situations that they felt were the most stressful in their academic and personal lives. Separating the academic from the personal dimension of the stressors was considered "to force a wider range of responses and to overcome the tendency of students to see everything as related to their immediate academic environment" [1].

The present study explores online learners' stress relating to academic and personal issues. Therefore, the survey was announced after students had experienced some kind of stressrelated life event. The study was careful not to choose stressstricken periods (e.g., deadlines for assignments or exams). The web version of the departmental survey was posted on the website of the Department of Counseling Psychology (at Korea Cyber University) approximately 4 weeks after the semester began. Participation was voluntary.

\subsection{Analysis}

The present study used a categorization method developed by researchers who have conducted extensive studies on college students' stress [1], [23], [24], [34]. The academic and personal stressors reported by the participants were independently coded by the two researchers of the present study to create the categories. First, the researchers familiarized themselves with the criteria for the categories. Second, the researchers discussed the results of the independently coded categories. The coded data were examined, and an agreement was reached about them. The initial evaluation produced $86 \%$ agreement on the coding of the data. Initial discrepancies were discussed carefully to improve reliability in subsequent codings. Differences in coding were resolved through discussion, and categories were revised accordingly. Inter-rater reliability was achieved by computing Cohen's Kappa values (Cohen's Kappa $=.083$ for academic stressors and Cohen's Kappa $=.082$ for personal stressors).

\section{RESULTS}

\subsection{Academic and Personal Stressors}

The three most frequently reported academic stressors were limited time and too many demands (33.7\%), the unfamiliarity of the online learning system (16.1\%), and managing class materials (10.9\%). 
Table 2. The frequency distribution of academic stressors in descending order

\begin{tabular}{lc}
\hline \multicolumn{1}{c}{$\begin{array}{c}\text { Stressor Type } \\
\text { (Abbreviated stressor type in parenthesis) }\end{array}$} & $\begin{array}{c}\text { Frequency } \\
\text { (Percent) }\end{array}$ \\
\hline $\begin{array}{l}\text { Limited time and too many demands (Time) } \\
\text { Unfamiliarity of online learning system }\end{array}$ & $55(15.7)$ \\
(Unfamiliarity) & \\
Effectively managing class materials (Manage) & $37(10.9)$ \\
Assignments (Assignments) & $25(7.3)$ \\
$\begin{array}{l}\text { Exams (Exams) } \\
\text { Mandated activism and discussion in class }\end{array}$ & $21(6.2)$ \\
(Participate) & $21(6.2)$ \\
Study anxiety (Anxiety) & $12(3.5)$ \\
Grades (Grades) & $12(3.5)$ \\
Taking courses (Taking Courses) & $11(3.2)$ \\
Ability to seek help (Seek help) & $9(2.6)$ \\
*Other & $23(6.8)$ \\
\hline
\end{tabular}

The three most frequently reported personal stressors were personal living environment (13.5\%), multiple roles (12.2\%), and balancing work and study (10.1\%). The frequencies of the academic and personal stressors are presented in Table 2 and Table 3, respectively.

Table 3. The frequency distribution of personal stressors in descending order

\begin{tabular}{lc}
\hline \multicolumn{1}{c}{$\begin{array}{c}\text { Stressor Type } \\
\text { (Abbreviated stressor type in parenthesis) }\end{array}$} & $\begin{array}{c}\text { Frequency } \\
\text { (Percent) }\end{array}$ \\
\hline $\begin{array}{l}\text { Living environment (Environment) } \\
\text { Multiple role as a family member, an }\end{array}$ & $40(13.5)$ \\
employee, and a student (Role) & \\
Balancing work and study (Balance) & $33(10.1)$ \\
$\begin{array}{l}\text { Personal adjustment as a student (Adjustment) } \\
\text { Finance (Finance) }\end{array}$ & $27(8.3)$ \\
No time to rest (Time) & $27(8.3)$ \\
Interpersonal issues at work (Interpersonal) & $23(7.0)$ \\
Health (Health) & $22(6.7)$ \\
Lack of confidence (Confidence) & $21(6.4)$ \\
Whether taking online classes is beneficial to & $19(5.8)$ \\
my future (Future) & $16(4.9)$ \\
Personal goal setting (Goal) & $14(4.3)$ \\
Fatigue (Fatigue) & $12(3.7)$ \\
Issues related to intimate relationships & $10(3.1)$ \\
(Intimate) & \\
*Other & $19(5.8)$ \\
\hline
\end{tabular}

\subsection{Age}

The results of the distributional analysis on age were not normally distributed, with a minimum of 23 and a maximum of 52, demonstrating a positive skewness. Thus, age is divided into three age groups: Age Group 1 (from 23 to 30), Age Group2 (from 31 to 37), and Age Group 3 (from 38 to 52). To investigate research question 1 , Pearson chi-square statistics were computed on academic stressors and Age Group. Only one result was significant, "managing class materials," for academic stressors $\left(X^{2}(2)=6.18, \mathrm{p}=.046\right)$. Age Group 1 indicated that managing class materials was one of their top academic stressors.
The following section describes academic stressor frequencies in relation to Age Group. The strongest academic stressors reported by Age Group1 are "too many demands and not enough time," "managing class materials," "mandated activism in class participation," and "the unfamiliarity of learning systems and environments." The strongest academic stressors reported by Age Group 2 are "the unfamiliarity of online learning systems and environments," "managing class materials," and "exams." Age Group 3 reported "the unfamiliarity of online learning systems," and "too many demands and not enough time" as the strongest academic stressors. "Managing class materials" and "mandated activism in class participation" were tied. Figure 1 shows the academic stressor frequencies grouped into the three age groups, Age Group 1, Age Group 2, and Age Group 3.

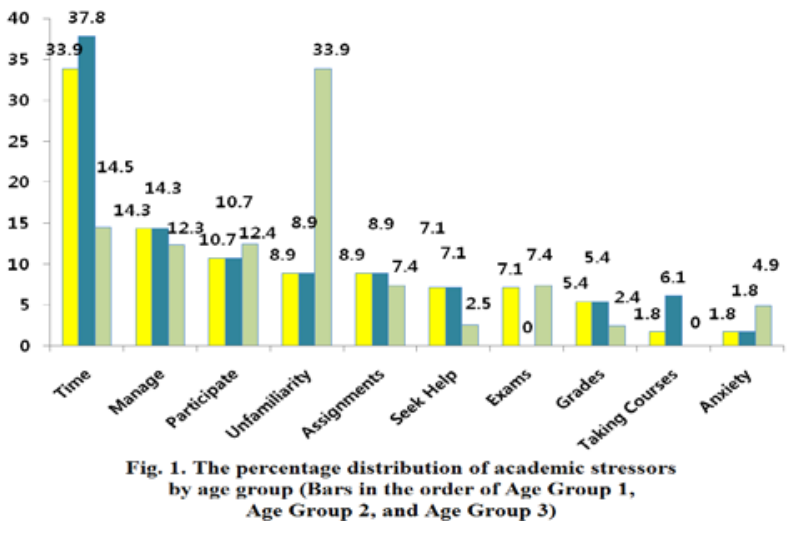

\subsection{Marital Status}

To test research question 3, Pearson chi-square statistics were computed on academic stressors and marital status. There were no significant relations between marital status and any of the academic stressor types.

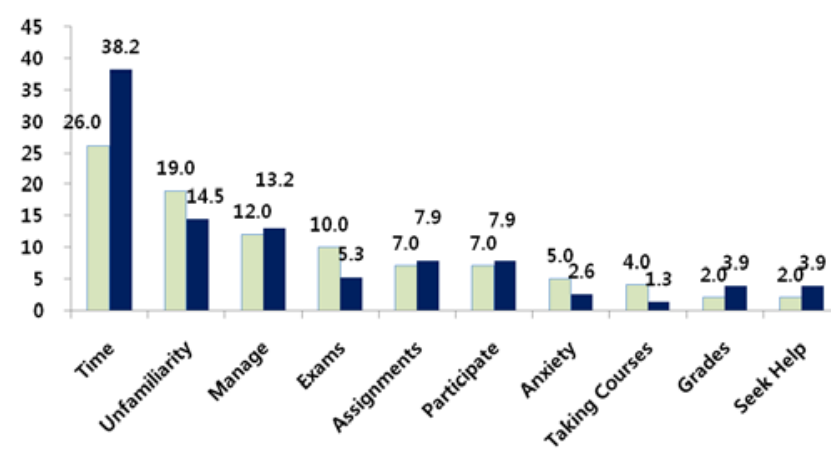

Fig. 3. The percentage distribution of academic stressors by marital status (Bars in the order of "Married" vs. "Single")

For academic stressors, both married and single students reported "time," "unfamiliarity," and "managing class materials" as the top two academic stressors. The results are shown in Figure 3.

To test research question 4, Pearson chi-square statistics were computed on personal stressors and marital status. No significant relations were found between marital status and any of the personal stressor types. 


\section{Demographic Variables}

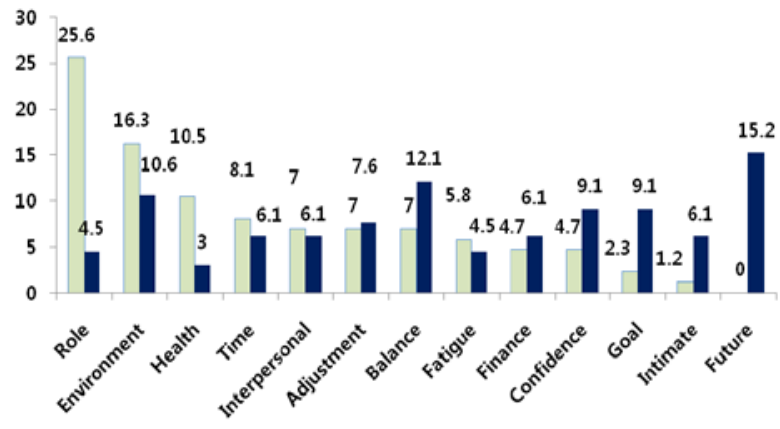

Fig. 4. The percentage distribution of personal stressors by marital status (Bars in the order of "Married" vs. "Single")

For personal stressors, married students reported "multiple roles," "living environment," and "health" as the top two stressors. Single students reported "concerns about the future," "balancing work and study," and "living environment" as the first or second stressors. The personal stressor frequencies of these two groups are presented in Figure 4. Although statistically not significant, the largest differences between these two groups were observed in "multiple roles," "concerns about the future," and "health."

\section{4 Change of Major}

To test research question 5, Pearson chi-square statistics were computed on academic stressors and change of major. There was a significant academic stressor relation in the number of frequencies between a history of changing majors and not having enough time to work on academics $\left(X^{2}(1)=7.20\right.$, $p<.01)$.

Those who changed majors indicated more of a lack of time to do course work. Figure 5 shows the percentage distribution of academic stressors by change of major in "Same Major" vs. "Changed Major" order.

For academic stressors, students who changed majors reported "too many demands and not enough time," "unfamiliarity," "managing class materials," and "assignments" as the strongest stressors. Students who had never changed majors reported "not enough time," "the unfamiliarity of online learning," "managing class materials," and "exams" as the top two academic stressors. The academic stressor frequencies of these two groups are presented in Figure 5.

The largest gaps between the two groups were found in "too many demands and not enough time" and "the unfamiliarity of the online learning systems."

To test research question 6, Pearson chi-square statistics were computed on personal stressors and change of major. There were no significant relations between a history of changing majors and any of the personal stressor types.

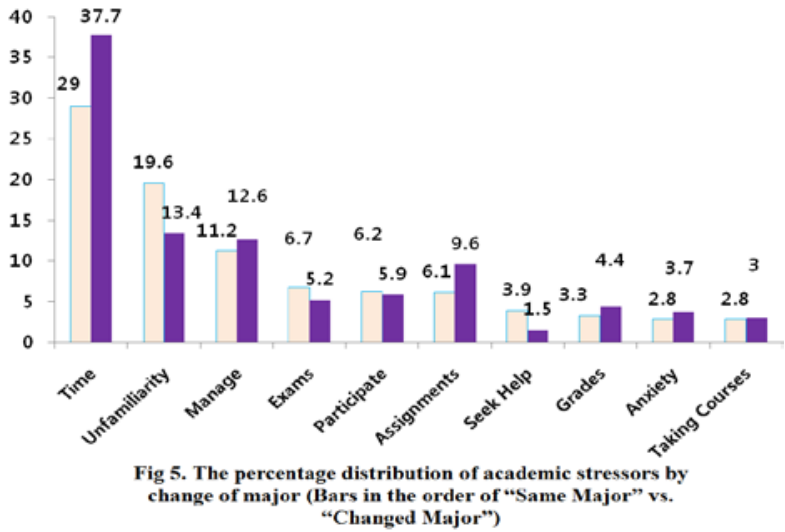

For personal stressors, same-major students reported "concerns about the future," "finance," "interpersonal relationships," and "issues of spousal support" as the top two stressors. Students who had changed their majors reported "finance," "future," "balancing work and family," and "multiple roles" as the top first or second stressors. Details on the frequencies between these two groups are presented in Figure 6.

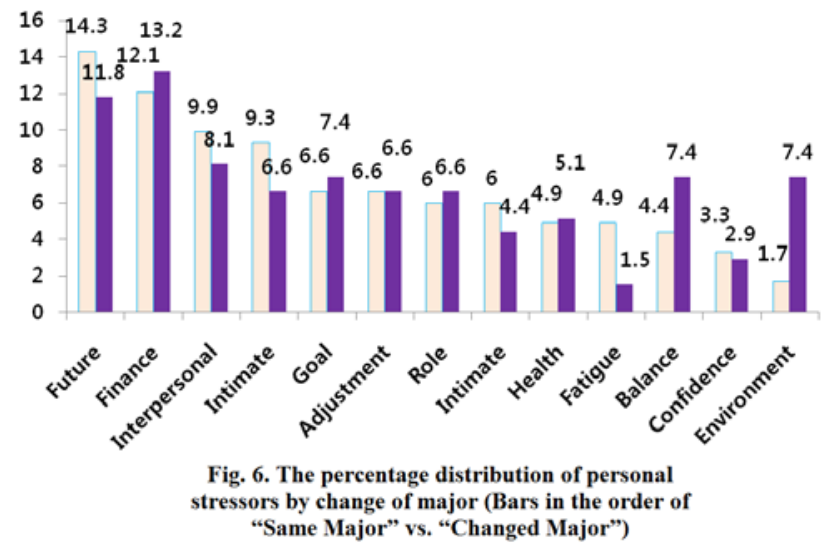

Among these stressors, the largest gaps between same major and different major students were found in "multiple roles" and "fatigue."

\section{CONCLUSION}

\subsection{Discussion}

This study has revealed that online university students with nontraditional life paths experience unique stressors reflecting their lifestyles. Their conflicting roles as a family member, an employee, and a student who may or may not have learned to maneuver online learning systems force online learners to deal with multiple work demands and dilemmas. Although this study was essentially exploratory and qualitative, its results demonstrate its significance One of the primary differences between the present study and previous studies on adult learners' pursuit of online education is that this one points to issues of mental health. Exploring samples of online university students and their stress is relatively rare. This study looked specifically at the stresses that can be pervasive in both the 
academic and personal areas of online university students' lives.

This study has also examined stressors connected to adult development and aging, unlike the studies on traditional college students; for example, the unfamiliarity of online learning systems was a threat to those who had not used the systems before entering online universities. The objective of this study was two-fold: (1) to examine the stressor patterns unique to and representative of online university students' in Korea and (2) to look for the common issues reflective of that groups' needs. The present study also suggests collaborative approaches to the promotion of online learning competence.

Overall, Korean online university students were faced with having to play the role of a student and other roles assigned to them. Limited time and an environment inconducive to proper functioning were also experienced by Korean online university students. Older students experience greater difficulty adapting to online learning systems. Younger students experience greater difficulty managing time, balancing work and study, and facing their multiple roles. These results suggest that older students may not experience time conflicts or deadlines as much as younger students do but that they may need to brush up on their computer and Internet navigating skills to become familiar with online learning systems.

Single students experienced greater difficulties with time issues than did the married students. It can be thus postulated that, although married students are faced with a variety of roles, they have learned to manage their time and set priorities more effectively than non-married students. Single students were also more concerned about their future than were married students and expressed concerns as to whether taking online courses would be helpful to their career and future. These findings could serve a basis for developing programs for online university students that would help their student life adjustment and career decision making.

Students who had changed their major seemed to have (1) greater concerns over managing their time, finding conducive study environments, and balancing work and study and (2) fewer concerns about their future and the unfamiliarity of online learning systems than those who had never changed their major. These findings point to the need to develop guidance programs for students in transition.

The findings assist an understanding of Korean online university students' struggles at both the group and cultural levels. The study selected age, change of major, and marital status as the grouping criteria for group-level investigations and to suggest strategies for institutional development, instructional planning, and student mental health services.

The findings of this study also provide cultural insights into gender-role expectations, cultural values on education, and Koreans' general anxiety about uncertainties. In light of this frame of analysis, the following issues can be addressed. To motivate students to improve their learning adaptability, student affairs professionals and faculty members need to constantly encourage students to stay motivated by framing their struggles and challenges as controllable factors. Online universities should also provide students with ways of enhancing their assertiveness and help-seeking behavior.

Students can also be motivated through the strategies suggested by attribution theorists. Emphasizing the fact that challenges and struggles are only temporary can give students a sense of control [47]. When students step into online learning communities, they aspire to certain goals. It is critical for students to articulate their goals and work toward them. It is equally important for schools to provide information and advice every step of the way, to help students overcome barriers and anxieties. Students can improve their coping skills by seeking help from the student welfare and counseling offices. Those concerned about navigating their school's systems can seek help from the academic assistance and technical support units. Making students aware of the available academic assistance and technical support can help them solve computerrelated problems and strengthen their ability to use web-based instructional materials.

Student motivation can be enhanced through various types of instruction. One way to motivate students is to offer live and synchronous classes so that students can interact directly with faculty and peers. Incorporating different approaches to teaching and learning can also be helpful. These approaches will help students not only overcome their boredom and fatigue but also learn materials effectively (e.g., problem-based learning, group-based learning). In fact, a study conducted by distance education researchers showed that lecture-based distance education programs can best be supplemented by multimedia and cooperative learning [2].

Although online university students reportedly have trouble allocating their online class attendance, they still benefit from the accessibility of online classes and study materials (or study guides) whenever they are needed. For example, a study has shown that more than half of its participants were satisfied with the fact that they could choose the best time to attend classes and obtain information from online classes more easily than from traditional school classes [15]. A recent alumni survey conducted by Korean Cyber University also shows that former students who had overcome situational barriers and persisted until they accomplished their goals reported a greater level of satisfaction [19]. These results demonstrate a possible link between low stress students and the accessibility of just-in-time learning.

Systemic approaches to enhancing motivation and understanding stressors should be considered to facilitate interactions among students. One way of providing help is allowing students to participate in online and offline departmental-level or school-level meetings held regularly or synchronously. Students could also take full advantage of student organizations and activities offline. Most online students resided not far from their school, facilitating attendance at offline meetings and workshops on their areas of interest while pursuing their degree. The limitation of this approach is that students living in different cities or abroad may not be able to take advantage of offline meetings and workshops. However, the development of education and information technology has been rapid and influential. Research practitioners have been studying ways of making online learning communities more "live" and inclusive through alternative online media, such as avatar pedagogy and pedagogical agents in online learning [10], [33]. The monumental progress being made in this area is encouraging. The study's findings have several implications for 
understanding the stressors online university students face and developing intervention programs.

First, government intervention needs to be considered. Government incentive funding plays an important role in Korea's lifelong education systems. Lifelong education was enacted recently, and its resource allocation seems to be in its infancy. Although funding allocation based on performance measures seems reasonable, online universities may lose their performance direction without educational norms. This was evidenced by a study conducted by a group from the Korea Education and Research Information Services [17] showing that online universities that received indirect or direct government funding support with clear directions performed better; this indicates that early government intervention and resource allocation are important in promoting quality online education.

External funding agencies such as government-affiliated organizations and government funding agencies too often allocate resources only after having examined how effectively online universities offer their classes. Funding should be allocated based not only on the effectiveness of the instructional management but also on the needs of the online universities and students. Given the relative paucity of government resource allocation to online universities and students, funding support should aim to raise public awareness of online education. Among examples of this approach are funds for the administration of schools, student scholarships, and endowment faculty funds.

There may not be a perfect approach to resource allocation. As lifelong education is an area of increasing public demand, however, online universities' contribution to widening public access to educational opportunities and their capacity to raise public awareness of online learning programs should not be left unattended. Government intervention and approaches can facilitate these effects.

Second, institution-level approaches should also be considered. Implementing strategic planning for Korea's online universities must involve school administrators, student affairs coordinators, and counselors, who will infuse student perspectives into all school-level functions. Being able to understand what online students face and what the school can offer are the key components in becoming competent online universities. Some insight into institutional planning, student affairs, and using counseling services can be gained from considering a partnership model, as that which serves as the basis for this research.

Institutional planning often involves taking various institutional characteristics into consideration and conducting a series of campus climate surveys, alumni surveys, and needs analyses for student/faculty/administrators. Student experience and perceptions have been important factors in developing institutional and instructional policies [5], [45], [46]. A previous study shows that nontraditional students suffered a greater level of stress due to their family obligations, their need to balance work and study, and their struggle to control time and financial issues [32]. When instituting policies in colleges and universities, a collaborative approach needs to be used. It is particularly important to examine whether online universities take the perceptions of student groups into consideration when designing student services and programs. In our study, single and younger students (Age Group 1) were more concerned about their future than were married and older students (Age Group2). Married and older students were more concerned than were single or younger students about their multiple roles as a mother or father, counselor, tutor, disciplinarian for their children, care-provider for ailing elderly parents-in-law, housekeeper or worker, spouse, and student. In addition, students who had changed their majors seemed to need more guidance than those who had not in dealing with academic demands, balancing roles, and prioritizing tasks. These personal and academic struggles expressed by certain age groups, by students with and without a history of changing majors, and by married and non-married groups can be mitigated through workshops, training, and orientations for online university students. Furthermore, the aforementioned institution-level programs and activities can be implemented in collaboration with counseling services.

Older students seemed to have a greater level of anxiety over the unfamiliarity of online learning systems. Many older students feel overwhelmed by the amount of class material and feel that they lack memory skills and study strategies. Counselors may need to focus more on the "identity model" than the "deficit model." Counselors need to help older students feel that they are not deficient in skills but have gained plenty of experience from which they can draw. Although their ability to memorize novel concepts may not be as strong as it was, older students have plenty of life experience that they can use.

Counselors can also be useful by emphasizing prevention over remediation. Assertiveness and help-seeking training may help students acquire a preventionist mindset. Being able to seek help in class and stand up for their needs and interests in school will naturally promote a sense of control and a healthy coping style when students are faced with barriers that cause stressors [14], [17].Third, instructor-level interventions must be considered. Instructors could be useful in helping students improve meta-skills, such as collaborative problem solving, reflective inquiry, and critical and positive thinking skills [41]. By carefully reading what is written on the discussion board, writing responses reflecting deep thinking, and understanding the context being discussed, students will be able to share and promote an online community feeling. In addition, students will learn how to separate emotion from thoughts by practicing the technique of not jumping to conclusions too quickly when a negative event occurs. This process will help students overcome anxieties related to online learning systems and study skills. Instructors can be useful in helping students formulate positive, stress-lowering attitudes. In conclusion, considering student characteristics in designing online courses is a valuable area for online university instructional development. That which makes students more adaptable can be fostered when online course development takes students' background characteristics, such as change of major, marital status, and age, into consideration.

\section{2 Limitations and Directions for Future Studies}

This study's findings need to be considered in light of several limitations. The sample was drawn from students taking 
counseling psychology courses (as a convenience sample). The responses may be distinct from those of the general online university student population. Future research should replicate this study using a sample representing a more diverse population.

Future studies may need to identify the effects of studentfriendly environments on students' levels of stress and coping skills. If online universities provide programs and services intended to have positive effects on student well-being, the effects will be greater in those schools than in those without such intervention programs.

It may be helpful to test the hypothesis that students with extensive full-time employment experience may be more adaptable in coping with their stress. It may also be helpful to explore the link between the learning environment and students' stress level and academic motivation. Specifically, students who belong to online universities that are better financially supported by the government and are active in collaborative relationships with the offices of the institutional planning, counseling centers, and teaching and learning centers may be more satisfied with their learning environment and produce better learning outcomes. Most importantly, researchers and administrators of online universities need to be aware that the effectiveness of online learning should not be studied without taking students' motivation and well-being into consideration.

\section{REFERENCES}

[1] Archer, J. \& Lamnin, A., “An investigation of personal and academic stressors on college campuses,” Journal of College Student Personnel, vol. 26, 1985, pp. 210-215.

[2] Boling, N. \& Robinson, D., "Individual Study, Interactive Multimedia, or Cooperative Learning: Which Activity Best Supplements Lecture-Based Distance Education?” Journal of Educational Psychology, vol. 91, no.1, 1999, pp. 169-174.

[3] Butler, C. B., “Age-related paradigms,” Directions for Adult and Continuing Education, vol. 108, 2005, pp. 6168.

[4] Bye, D., Pushkar, D., \& Conway, M., "Motivation, interest, and positive affect in traditional and nontraditional undergraduate students,” Adult Education Quarterly, vol. 57, 2007, pp. 141-158.

[5] Callender, C. \& Kemp, M., "Changing student finances: income, expenditure and the take-up of student loans among full- and part-time higher education students in 1998/1999” (London, Department for Education and Employment), 2000.

[6] Carney, C. G., Peterson K., \& Moberg, T. F., "How stable are student and faculty perceptions of student concerns and of a university counseling center,” Journal of College Student Development, vol. 31, 1990, pp. 423-428.

[7] Chung, Y. S., \& Kim, S., "Status of stress and problemsolving ability on flow in cyber class," The Journal of the Korea Contents Association, vol. 11, no. 7, 2011, pp. 179191.

[8] Fairchild, J., "Multiple roles of adult learners," New
Directions for Student Services, vol. 102, 2003, pp. 11-16.

[9] Foreman, J. “Avatar pedagogy,” The Technology Sources Archives. http://technologysource.org/article/avatar_peda gogy/ 1999.

[10] Frisch, M. B., "Role-play training as a tool in social skills assessment,” Perceptual and Motor Skills, vol. 67, 1988, pp. 483-490.

[11] Gallagher, R. P., Galvin, A., \& Kelleher, K., "The personal, career, and learning skills needs of college students,” Journal of College Student Development, vol. 33, 1992, pp. 301-309.

[12] Heppner, P. P., Kivlighan, D. M., Jr., Good, G. E., Roehlke, H. J., Hills, H. I., \& Ashby, J. S., "Presenting problems of university counseling center clients: A snapshot and multivariable classification scheme," Journal of Counseling Psychology, vol. 41, 1994, pp. 315-324.

[13] Jacobson, R. R., "Differences between traditional and nontraditional students on the Motivated Strategies for Learning Questionnaire," Dissertations Abstracts International, 67(3-A), 2000, 879. (UMI No. 9965734)

[14] Justice, E. M. \& Dornan, T. M., "Metacognitive differences between traditional-age and nontraditionalage college students,” Adult Education Quarterly, vol. 51, 2001, pp. 236-249.

[15] Kang, H., Kim, M., \& Kim, H., “Online students’ needs and satisfaction toward online university," Kyonghee University Journal of Research on Collegial Life, vol. 8, 2003, pp. 71-105.

[16] Kinman, G. \& Jones, F., "Lay representations of workplace stress: What do people really mean when they say they are stressed?” Work \& Stress, vol. 19, no.2, 2005, pp. 101-120.

[17] Kim, S. K., Park, S.K., \& Song, J.S. A Study on the Establishment of E-learning Service Center for Universities. Unpublished technical report. Korea Education and Research Information Services, 2003.

[18] Kipper, D. A., "The effect of two kinds of role playing on self-evaluation of improved assertiveness," Journal of Clinical Psychology, vol. 48, 1992, pp. 246-250.

[19] Korea Cyber University. Student Satisfaction Survey. Unpublished technical report. 2006.

[20] Lazarus, R. S. \& Folkman, S., Stress, Appraisal and Coping. New York: Springer. 1984.

[21] Lee, I. S. "Korean content management in e-higher education: here and hereafter," Educational Technology Research and Development, vol. 54, no. 2, 2006, pp. 209-219.

[22] Lee, J. A., "Study on the curriculum specialization for the growth of cyber universities," Korean Journal of Computing Education, vol. 8, no 1, 2005, pp. 43-53.

[23] Lee, B. R., Lee, J. H., \& Chung, I. S., "Current status of cyber education in Korean higher education and quality control: The year 2002,” Korean Journal of Educational Research, vol. 41, no.3, 2003, pp. 541-569.

[24] Lee, D.H., Kang, S., \& Yum, S., “A qualitative assessment of personal and academic stressors among Korean college students: An exploratory study,” College Student Journal, vol. 39, 2005, pp. 442-448.

[25] Lee, D. \& Kang, S., "Perceived usefulness and outcomes 
of Intranet-Based Learning (IBL): Developing asynchronous knowledge management systems in organizational settings," Journal of Instructional Psychology, vol. 32, 2005, pp. 68-73.

[26] Lee, M. \& Chung, H., "Development of adolescent university entrance examination stress scale,” Korean Journal of Developmental Psychology, vol. 10, no. 1, 1997, pp. 144-154.

[27] Lee, S. C. \& Keith, P. M., "The transition to motherhood of Korean women," Journal of Comparative Family Studies, vol. 30, 1999, pp. 453-470.

[28] Lengrand, P. An Introduction to Lifelong Education. Paris, UNESCO, 1970.

[29] MacKay, C. J., Cousins, R., Kelly, P. J., Lee, S., \& McCaig, R. H. "Management standards and work related stress in the UK: Policy background and science,” Work \& Stress, vol. 18, 2004, pp. 91-112.

[30] Morris, E. A., Brooks, P. R., \& May, J. L., “The relationship between achievement goal orientation and coping style: traditional vs. nontraditional college students,” College Student Journal, vol. 37, no. 1, 2003, pp. 3-8.

[31] Merriam, S., "How adult life transitions foster learning and development," New Directions for Adult and Continuing Education, vol. 108, 2005, pp. 3-13.

[32] Moreau, M. P. \& Leathwood, C., "Balancing paid work and studies: Working (-class) students in higher education," Studies in Higher Education, vol. 31, no. 1, 2006, pp. 23-42.

[33] Moreno, R. \& Flowerday, T., “Students' choice of animated pedagogical agents in science learning: A test of the similarity attraction hypothesis on gender and ethnicity," Contemporary Educational Psychology, vol. 31, 2006, pp. 186-207.

[34] Murphy, M. C. \& Archer, J., "Stressors on the college campus: A comparison of 1985-1993," Journal of College Student Development, vol. 37, 1996, pp. 20-28.

[35] Nam, S. Z., "Effectiveness and problems of distance learning," International Journal of Contents, vol. 6, no. 1, 2010, pp. 12-19.

[36] National Center for Educational Statistics. $\quad$ http://nces.ed.gov/programs/coe/2002/an alyses/ nontraditional/sa01.asp 2002.

[37] Oh, Y.S. "A structure of personalized e-learning system using on/off-line mixed estimations based on multiplechoice items,” International Journal of Contents, vol. 5, no. 1, 2009, pp. 51-55.

[38] Rudestam, K. E., "Distributed education and the role of online learning in training professional psychologists," Professional Psychology: Research and Practice, vol. 35, no. 4, 2004, pp. 427-437.

[39] Schlossberg, N. K., Waters, E. B., \& Goodman, J. Counseling Adults in Transition. ( $2^{\text {nd }}$ ed.) New York: Springer. 1995.

[40] Skar, P., "Chaos and self-organization: Emergent patterns at critical life transitions," Journal of Analytical Psychology, vol. 49, no. 2, 2004, pp. 243-262.

[41] Smith-Jentsch, K. A., Salas, E., \& Baker, D. P., "Training team performance-related assertiveness," Personnel
Psychology, vol. 49, 1996, pp. 909-936.

[42] Swenson, C. D., "Graduate degree programs and distance education,” New Directions for Adult and Continuing Education, vol. 67, 1995, pp. 51-59.

[43] Tweedell, C. D., "A theory of adult learning and implications for practice," Chicago, IL: Annual Meeting of the Midwest Educational Research Association. (Eric Document Reproduction Service No. Ed 446 702). 2000.

[44] Van Derdoef, M. \& Maes, S., "The job demand-control (support) mode and psychological well-being: A review of 20 years of empirical research,” Work \& Stress, vol. 13, no. 2, 1999, pp. 87-14.

[45] Van der Linden, D., Keijsers, G. P. J., Eling, P., \& van Schaijk, R., "Work stress and attentional difficulties: An initial study on burnout and cognitive failures,” Work \& Stress, vol. 19, 2005, pp. 23-36.

[46] Vizcarro, C. \& Yániz, C., "Impact of the European harmonisation process on the educational development of university teachers in Spanish universities,” International Journal for Academic Development, vol. 9, no. 2, 2004, pp. 181-193.

[47] Weiner, B., "Principles for a theory of student motivation and their application within an attributional framework," In R. C. Ames \& C. Ames (Eds.), Research on Motivation in Education: Vol.1. Student Motivation. 1984 (pp. 15-38). San Diego, CA: Academic Press.

[48] Watts, C., "The effects of term-time employment on academic performance,” Education and Training, vol. 44, no. 2, 2002, pp. 67-75.

[49] Yang, J., \& Park, J., “A study on platform development for Web 2.0-based e-learning," International Journal of Contents, vol. 6, no. 1, 2009, pp. 1-8.

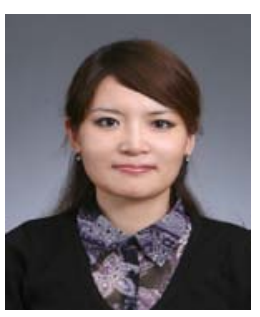

\section{Sunwoo Kang}

She received her M.S. in Educational and Counseling Psychology and her Ph.D. in Educational Psychology from the University of Kentucky. Her areas of research interests include intercultural communication and cross-cultural differences in cognition, emotion, and motivation. She is currently a senior researcher at the Catholic University of Korea and an affiliated professor at Korea University of Technology and Education.

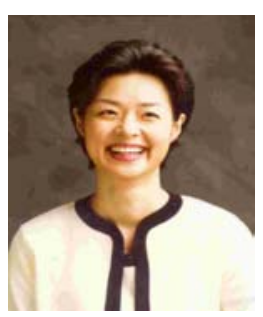

Young Sun Chung

She received B.S. and M.S in the department of Child and Adolescent Counseling at Sung Kyun Kwan University, Korea in 1993, 1996, respectively. She received Ph.D. in Educational Psychology at Texas A \& M University in 2001. She is currently an associate professor in the department of Counseling Psychology at Korea Cyber University. Her research interest includes counseling, mental health, and lifelong education. 